banking, social interaction and music among others, the factors influencing a possible use of personal safety apps by tertiary students specifically face a paucity of the literature. Industrial marketing managers and designers are required to understand how online consumers make sense of the value of unfamiliar, technology-driven products to make use of them. When features of technologies match particular characteristics of targeted markets, marketers and designers can decide the suitable investments in design and the best level of consumer engagement in design development (Park et al. 2015).

This article therefore aims to identify the factors influencing the adoption of mobile personal safety applications by college students in Johannesburg, South Africa.

\section{Theoretical foundation}

Theoretically, the technology acceptance model (TAM) originally developed by Davis (1998) is one of the theories that attempts to explain why individuals adopt technology such as apps. Technology acceptance begins with external variables, often cognitive in nature, which influence perceived usefulness (PU) and the perceived ease of use (PEOU), which in this case would relate to the adoption of safety apps. Perceived usefulness refers to the degree to which an individual believes that using technology will assist in improving their performance, whereas PEOU is explained as the extent to which a person regards that he or she will be able to utilise a given technology without exerting much effort - also termed as self-efficacy (Cho et al. 2014). The TAM depends on the main hypothesis of the theory of reasoned action (TRA), which discusses how a person intends to be engaged in a particular behaviour that is determined by cognitive factors. Komiak and Benbasat (2006) point out that cognition has an impact on a wide range of safety information systems platforms usage, acceptance and adoption.

A study conducted by Kim and Yoon (2014) made use of TAM to research antecedents affecting app use. The variables researched included perceived informative usefulness, perceived entertaining usefulness, user review and perceived social usefulness, PEOU, attitude towards app usage and perceived cost effectiveness. Verkasolo et al. (2010) found that enjoyment and efficiency could be used to explain users' and non-users' intentions to make use of smartphone apps. The generational cohort theory (GCT) posits that groups of people can be clustered based on placement in the historical cycle that includes specific events that shape the attitudes and behaviour of each cohort. The GCT previously formulated by Schewe and Meredith (2004) is now commonly applied to market analysis to define and describe generational cohorts.

Given that the millennial generation is at present the primary focus of popular media and markets, this theory becomes applicable to the study.

\section{Use of digital technology by millennials}

South Africa boasts of a population of almost 57 million people. Mid-year population estimates show that over 20 million South Africans are aged 15-34 years old (Stats SA 2017a). Given that it is a significant number of people who are increasingly growing in terms of their purchasing power, they are often a primary target for various commercial products including mobile applications.

The vast majority of South African students attending post-secondary education fall between the ages of 18 and 35 (DHET 2018), which means that they largely overlap with the Generation Y category - millennials. The definitions of millennials vary, but generally millennials are described as the individuals who were born between 1981 and 1999 (Bolton et al. 2013). Among the key characteristics of this generation is their search for personal rewards, an affinity for flexibility, the need for participation without paying attention to outcomes and absence of brand loyalty (McCormick 2015; Ogbeide et al. 2013).

Millennials are different from other generations in that they adapt quickly to innovative changes in technology (Purani, Kumar \& Sahadev 2019), therefore being the most technologically savvy.

Millennials are immersed in technology and use it not only for personal reasons, but also to engage with organisations and brands (McCorkindale, DiStaso \& Sisco 2013; Moore 2012). South African millennials too have an inclination to engage with brands online (Azionya 2015; Oksiutycz \& Kunene 2017). This age group is technology-dependent, and they are likely to adopt technology in their lives for a variety of purposes: from accessing the health services (Petaschnick 2017) and banking (McCormick 2015) to getting news (Ferguson \& Greer 2016). Millennials have shown the propensity to use technology to communicate, connect with others and to share content (Bolton et al. 2013). Mobile apps usage is to a large extent driven by utilitarian motivations (Verkasalo et al. 2010).

For millennials, technology is a necessity, not a luxury (Ogbeide et al. 2013); hence, they embrace the technological capabilities of smartphones. The majority of millennials own a smartphone (Petaschnick 2017). Smartphone subscriptions in South Africa increased by $72.9 \%$ from 2016 to 2017 (ICASA 2018). About 20-22 million people in South Africa use a smartphone, which accounts for about one-third of the country's population (Statista 2020). According to Verkasalo et al. (2010), smartphones facilitate the potential adoption of new mobile applications. Parallel to the spread of the adoption of mobile devices, apps have accomplished great growth over the years (Kim, Kim \& Rogol 2017). Voigt (2013) stated that global revenue from mobile apps was anticipated to grow more in 2015. Some researchers argue that there is still a need to study the adoption of technological innovations among various age cohorts (Kwateng, Atiemo \& Appiah 2018; Vesanen 
2018; Thusi \& Maduku 2020). This is because research has proved that behavioural intention is the best predictor of actual use, with behavioural intention being the main factor indicating individual mobile services usage (Mafe Ruiz, Sanz Blas \& Fernando Tavera-Mesías 2010).

However, Alam et al. (2020) argue that although Generation Y individuals are more likely to use applications, they take into consideration the price value, defined as 'consumers' cognitive trade-off between the perceived benefits of the applications and the monetary cost for using them' (Venkatesh, Thong \& Xu 2012:161). Even when Generation Y individuals use applications, the use is not sustained if they do not accrue any discounts from the continuous use of technology (Baabdullah 2018). As an age cohort, regarding the use of mobile apps, they are viewed as the most difficult both to attract and retain (Moreno et al. 2017; Tan \& Lau 2016). Steele et al. (2009) posit that cost may be the most important determinant influencing the adoption of technology. For gender use of technology, Tarhini, Hone and Liu (2014) suggest that, in general, women were more likely to have a higher technology anxiety and lower self-efficacy when dealing with technology than men. Self-efficacy with regard to technology is the perception by which a person regards that he or she will be able to utilise a given technology without exerting much effort (Cho et al. 2014). Furthermore, Ghalandari (2012) argues that gender may mediate the effects of facilitating conditions on the users' behaviour associated with the adoption of new technology. Women are more likely to be more cautious, rational and sensitive to risks of using technologies (Alam et al. 2020).

\section{Personal safety and personal safety apps}

Arguably, the use of safety apps is closely related to the perceptions of safety. Safety perceptions are influenced by individual, social and environmental factors. Among the factors affecting individual safety, perceptions are demographic characteristics, culture, level of urbanisation and the type of neighbourhood. For example, people with disabilities and women are more concerned about safety in public places (Delbosc \& Currie 2012). Previous studies (Batra 2008; Jansson et al. 2013) highlight that feeling unsafe outdoors, or when using public transport is often linked to the fear of crime. Stats SA's (2017b) Victims of Crime Survey (VOCS) shows that because of fear of crime, one in three households in South Africa does not go to open spaces or walk alone in parks, and one in five households does not allow their children to play on their own in the area they live. Provincially, the majority (52\%) of households in the province of Northern Cape indicated that they do not go to open spaces or walk alone in parks in the area they live because of fear of crime, although only $13 \%$ of households in Limpopo province said the same. In another study, McCarthy, Culfield and O'Mahony (2016) concluded that travel safety associated with the use of public transport influences people's perceptions of individual safety. People who use public transport have increased sense of crime risks.

Safety-related applications are said to be becoming the fastest growing segment of the industry (Statista 2015). Mobile safety apps have the capability to serve as a powerful medium that communicates the details and experiences of consumers in possession of personal safety apps (Kim et al. 2017). Smartphone personal safety applications (apps) are tools that can make a person's personal life better (Dube 2013). These apps are not discriminatory in terms of whether they are used by a man or woman, a person going to new places or travelling alone. This is because being isolated from other people has the potential to create dangerous situations. Research revealed that carrying a mobile phone increases the sense of safety outdoors while travelling, although downloading safety apps is considered a supplementary safety technology (McCarthy et al. 2016).

In terms of adoption, it is paramount to know the circumstances influencing the consumers' adoption of safety apps to be able to figure out if consumers are making rational choices to maximise their safety. Previous mobile device studies show that consumers usually refer to reviews of an app and examine the star rating before installing it (Harris, Brookshire \& Chin 2016). Advertising, word of mouth, expertise, categorisation and product characteristics fully influence adoption rates and patterns. Studies show too that university students adopt smartphone technology faster than any other group (Lepp, Barkley \& Karpinski 2014). Mobile marketers are looking for ways to provide value through mobile apps. As the app market is expected to continue evolving, the goal of designers and marketers should be to design apps for the world as it stands, rather than the world as one envisions it to be (Barkhuus \& Polichar 2011).

Thus, much research has been dedicated to the development, accessibility and patterns of use of apps in general by millennials. However, there is a paucity of studies about the use of personal safety apps and specifically the challenges posed in developing societies such as South Africa, regarding adoption by millennials. Thus, the present article attempts to understand the challenges faced by students at tertiary institutions affecting their adoption of existing personal safety apps such as Cell 411, FindU, Namola and Shake2Alert.

Potter et al. (2020) point out that the unique experiences of tertiary students present a challenge to the use of personal safety apps. One of the challenges of using personal safety apps by tertiary students is that many of them lack the necessary resources, which affects prioritisation of and affordability to use personal safety apps.

In addition, tertiary institutions are unable to secure funding dedicated to implementing prevention and response 
strategies such as providing and running personal safety apps, as well as creating buy-in from students (Potter et al. 2020:46S). In terms of gender, studies have found that women are more likely to be concerned by security issues than men, yet men pay more attention to the effectiveness of the technology that they use (Tarhini et al. 2014).

Some researchers have suggested interventions to mitigate the challenges of adopting use. Thusi and Maduku (2020) argue that millennials will adopt mobile banking apps if they trust the app's systems and the institutions offering the service. Maduku (2016) stressed that customers who perceive electronic channels (such as mobile apps) as easy to use are likely to report high levels of trust in the institutions that offer them. They argue that the institutions, which offer apps, need to increase publicity about the products available, by using promotional messages that increase awareness and emphasise the benefits of mobile apps, thus appealing to millennials' performance expectancy motivations. Alam et al. (2020) suggest that decision makers should focus on wordof-mouth communication as a tool for promoting services via smartphones. Thusi and Maduku (2020:8) argue 'most studies addressing mobile apps acceptance and use have focused on Western and Asian countries. Less attention has been paid to other regional contexts such as Africa'. This article explores, specifically for students in tertiary institutions in the South African context, how factors such as costs, trust, expectations and other perceptions could affect the adoption of personal safety apps.

\section{Methodology}

A cross-sectional descriptive study by using a survey research design was conducted. Saunders, Lewis and Thornhill (2003) describe surveys as structured collection of data from sizable populations. The researchers used a descriptive survey with the aim 'of providing an accurate representation of phenomenon at one point in time' (Collis \& Hussey 2009:77).

The population of the study was students who attend postschool (tertiary) educational institutions in Johannesburg. The South African post-school education system consists of higher education institutions that comprise public and private universities, technical and vocational education and training (TVET) colleges, community education and training (CET) colleges and private colleges.

Although there is no data on the number of tertiary students in Johannesburg, based on the data provided by the DHET (2018) on the numbers of post-school students in the Gauteng province where Johannesburg is situated, it can be estimated that the population of students attending colleges is well over 100 000. Multistage sampling was used in the study. Initially, 10 colleges and universities in Johannesburg were selected, by using purposive heterogeneous sampling approach. The sample comprised large and small universities and colleges including three public higher education insititutions (HEIs), four private HEIs, one TVET college and two private colleges. The University of Johannesburg is one of the largest HEI in Johannesburg with nearly 50000 students studying on four campuses situated in various suburbs of the city. It was decided that each of the campuses would be treated as a separate sampling site. Johannesburg was relevant for the study of personal safety apps, because the 2018/2019 South African Police Crime Statistics revealed that Johannesburg Central is the second worst crime-ridden region in the country after Cape Town Central with 14058 cases (Crime Stats SA 2019). Tertiary institutions were studied because in addition to tertiary institutions being situated around crime hotspots, students adopt apps faster than other groups (Lepp et al. 2014).

During the second stage of sampling, purposive heterogeneous sampling was employed again. Saunders et al. (2003:175) explain that heterogeneous sample 'enables a researcher to collect data and explain key themes that can be observed'. Six field workers went to the selected campuses intending to obtain at random around 20 responses from students at each site. The field workers were asked to approach students of different gender, age and race. In-person data collection resulted in a high response rate; 203 valid responses were obtained.

Sample size depends on the purpose of the study and the nature of the population under investigation. The sampling frame was not available to the researchers; hence, nonprobability sampling was used. Cohen, Manion and Morrison (2007:102) suggest that survey research should have 'no fewer than 100 cases in each major subgroup and twenty-fifty in each minor subgroup'. As college students in Johannesburg are the only major subgroup in the study, and 20 responses were collected at each site, our sample size fulfils the above requirement.

A multi-scale, structured, self-administered questionnaire was used to collect the data. The questionnaire had four sections. Section A solicited biographical information such as gender, age, college attended, residence and the primary mode of transport used. Section B consisted of questions on safety perceptions, Section C asked about attitudes about the adoption of technology and Section D consisted of questions about intentions to use personal safety apps. The Likert scale was used in sections B-D. In addition, the questionnaire had questions about the actual use of personal safety apps and familiarity with specific safety apps. The questionnaire also had an open question requesting to indicate three barriers to downloading safety apps.

Data were analysed with IBM SPSS (statistical package for the social sciences) Version 26. An exploratory factor analysis (EFA) was used to identify a smaller set of latent factors, which represent the larger set of variables (Williams, Onsman \& Brown 2010). According to Henson and Roberts (2006): 
Although the researcher may have some conceptualization of what factors may be present in the data, such as when items are developed to measure expected constructs, EFA generally does not consider a strong a priori theory. (p. 395)

Independent $T$-tests were conducted to identify possible gender differences between responses. In addition, a one-way analysis of variance (ANOVA) was conducted to ascertain whether factors such as age, place of residence and the primary mode of transport used influenced the responses. Reliability was tested by means of Cronbach's alpha.

\section{Ethical considerations}

This article followed all ethical standards for carrying out research without direct contact with human or animal subjects.

\section{Results \\ Sample characteristics}

Descriptive statistics used to provide sample characteristics show that almost half of the participants (50\%) were aged between 18 and 22 years, 33\% ranging from 23 to 27 years, $11 \%$ from 28 to 31 and $6 \%$ from 31 to 35 years. Most of the participants live in suburbs (27\%) and townships (29\%) surrounding Johannesburg with a large number of $26 \%$ hailing from the city centre. Of the participants, $12 \%$ were residents of the university or college residences $(12 \%)$, whereas others travelled from informal settlements $(6 \%)$. This means that the majority of the participants, over $60 \%$, commute between their places of residence to their institutions of study and therefore may find the need for using personal safety apps, in terms of their experiences and perceptions towards personal safety. Most of the participants indicated that they had personally experienced a threat to their personal safety (78\%) and that their peers had experienced threats too (89\%), as well as their family members $(76 \%)$. In terms of gender-related views, they thought that women encountered a higher risk of facing crime in Johannesburg (97\%) than men (78\%).

\section{Intention to download personal safety apps}

The responses summarising the intentions to download personal safety apps are presented in Table 1.

The majority of participants $(89.6 \%)$ agreed that they would download a safety app if it would meet their expectations. Most of the participants (91\%) indicated that they would pay for a personal safety app that ensures easy access to emergency services including police and fire departments among others. A large number of the participants (83\%) indicated that they would be ready to download an app that is recommended by their friends. They would also be willing to download an app if it would ensure their personal safety $(84 \%)$, if they have used a similar one before (56\%), if it is free $(88 \%)$, if it had good online reviews $(82 \%)$, if it is linked to personal medical aid $(79 \%)$, linked to a reputable organisation $(83 \%)$ or is linked to government emergency services (79\%).

\section{Use of personal safety apps}

Most of the participants indicated that they have never downloaded or used a personal safety app (85\%), while the remaining $15 \%$ stated that they have. Although only $3 \%$ of all participants do not own smart devices, $80 \%$ indicated that they use smartphones for accessing the Internet and social media, $8 \%$ mini tablets, $6 \%$ tablets and 3\% laptops. Most of the participants (89\%) have never used a personal safety app; only $11 \%$ have used. This is reflected in their responses to a question asking them which personal safety apps they know.

More than half of the participants (65\%) were not familiar with any personal safety apps. The better known app, out of My SOS, Cell 411, FindU, Namola and Shake2Alert, was My SOS with $21 \%$ participants acknowledging knowledge and the rest distributed across the others.

TABLE 1: Responses on intentions to download personal safety apps $(n=203)$.

\begin{tabular}{|c|c|c|c|c|c|c|}
\hline Statement & Variable & Strongly disagree & Disagree & Agree & Strongly agree & Total \\
\hline \multirow[t]{2}{*}{ D1_1. I would download a personal safety app if it meets my expectations. } & Count & 4 & 17 & 93 & 89 & 203 \\
\hline & Row $N(\%)$ & 2.0 & 8.4 & 45.8 & 43.8 & 100.0 \\
\hline \multirow{2}{*}{$\begin{array}{l}\text { D1_2. I would download a personal safety app because I used a similar app } \\
\text { before. }\end{array}$} & Count & 6 & 84 & 83 & 30 & 203 \\
\hline & Row $N(\%)$ & 3.0 & 41.4 & 40.9 & 14.8 & 100.0 \\
\hline \multirow{2}{*}{$\begin{array}{l}\text { D1_3. I would download a personal safety app because I believe in using any } \\
\text { tools that increase my personal safety. }\end{array}$} & Count & 2 & 30 & 81 & 90 & 203 \\
\hline & Row $N(\%)$ & 1.0 & 14.8 & 39.9 & 44.3 & 100.0 \\
\hline \multirow[t]{2}{*}{ D1_6. I would download a personal safety app recommended by my friends. } & Count & 4 & 31 & 94 & 74 & 203 \\
\hline & Row $N(\%)$ & 2.0 & 15.3 & 46.3 & 36.5 & 100.0 \\
\hline \multirow[t]{2}{*}{ D1_7. I would download a personal safety app that has good online reviews. } & Count & 5 & 31 & 85 & 82 & 203 \\
\hline & Row $N(\%)$ & 2.5 & 15.3 & 41.9 & 40.4 & 100.0 \\
\hline \multirow{2}{*}{$\begin{array}{l}\text { D1_8. I would download a personal safety app that is linked to my } \\
\text { medical aid. }\end{array}$} & Count & 4 & 38 & 82 & 79 & 203 \\
\hline & Row $N(\%)$ & 2.0 & 18.7 & 40.4 & 38.9 & 100.0 \\
\hline \multirow{2}{*}{$\begin{array}{l}\text { D1_9. I would download a personal safety app if it is linked to the } \\
\text { government medical emergency services. }\end{array}$} & Count & 4 & 39 & 84 & 76 & 203 \\
\hline & Row $N(\%)$ & 2.0 & 19.2 & 41.4 & 37.4 & 100.0 \\
\hline \multirow{2}{*}{$\begin{array}{l}\text { D1_10. I would download a personal safety app that is linked to reputable brand } \\
\text { or organisation. }\end{array}$} & Count & 5 & 30 & 76 & 92 & 203 \\
\hline & Row $N(\%)$ & 2.5 & 14.8 & 37.4 & 45.3 & 100.0 \\
\hline \multirow{2}{*}{$\begin{array}{l}\text { D1_11. I would download a personal safety app if it ensures an easy access } \\
\text { to emergency service (police, fire service). }\end{array}$} & Count & 3 & 16 & 62 & 122 & 203 \\
\hline & Row $N(\%)$ & 1.5 & 7.9 & 30.5 & 60.1 & 100.0 \\
\hline
\end{tabular}




\section{Factors influencing the use of apps}

To measure the adequacy of the sampling for factor analysis by using SPSS, the Kaiser-Meyer-Olkin (KMO) and Bartlett's test were performed (Table 2). The sampling is adequate if the value of KMO is > 0.6 (Pallant 2013). The KMO measure of sampling adequacy value was 0.877 , indicating that the sample size was adequate. Bartlett's test of sphericity was significant $\left(\chi^{2}=1652.181, p<0.001\right)$.

Eigenvalues $>1$ were used to determine the underlying component. The analysis yielded three factors with eigenvalues $>1$, explaining the total $53.056 \%$ of the variance in the data. According to Williams et al. (2010), there are no fixed thresholds for the cumulative percentage of variance, but $50 \%-60 \%$ is commonly accepted.

Factorial validity, assessed through factor analysis (Geffen \& Straub 2005), was used to determine construct validity. Seven questions related to safety perceptions, 12 question on the use of apps and 11 questions about intentions to use safety apps were analysed by using principal component analysis (PCA) and Varimax with Kaiser normalisation rotation. Principal component analysis is recommended if studies are not based on existing models (Williams et al. 2010). The three extracted factors were labelled as follows: Factor 1 was labelled Credibility of the app, and the factor contributed

TABLE 2: Kaiser-Meyer-Olkin and Bartlett's test.

\begin{tabular}{llc}
\hline Test & Variable & Value \\
\hline $\begin{array}{l}\text { Kaiser-Meyer-Olkin measure of } \\
\text { sampling adequacy }\end{array}$ & - & 0.877 \\
Bartlett's test of sphericity & Approx. chi-square & 1652.181 \\
& $d f$ & 190 \\
& Sig. & 0.000 \\
\hline
\end{tabular}

Approx., approximate; $d f$, degrees of freedom; Sig., significance. to $31.6 \%$ of the variance. Factor 2 was labelled Perceived utility of the app and explained $13.8 \%$ of the variance; factor 3 was named Safety experience and accounted for $7.5 \%$ of the variance.

A commonly used rule states that only variables with loadings greater than 0.4 on a factor should be considered 'significant' and used in defining that factor (Ford, MacCallum \& Tait 1986), to yield a valid factor analysis. Ten questions were removed because of factor loading below 0.4 . The factor Credibility of the app had nine items loading above 0.4, the factor Perceived utility of the app had eight items loading above 0.4 and Safety experience factor had three valid items (Table 3). No cross-loading items were present.

\section{Construct reliability}

Cronbach's alpha was used to establish reliability. Cronbach's alpha of the factors extracted by using an EFA, ranged from 0.633 to 0.904 (Table 4). Churchill (1979) suggests that a Cronbach's alpha value of 0.6 is acceptable. The lower level of Cronbach's alpha for the construct Safety experience can be attributed to a small number of items (3).

The independent T-test did not identify statistically significant differences in responses between genders. Similarly, the one-way ANOVA did not point to significant differences between respondents of different ages or those using different modes of transport.

TABLE 4: Cronbach's alpha for the three constructs.

\begin{tabular}{lcc}
\hline Construct & Cronbach's alpha & Number of items \\
\hline Credibility of the app & 0.904 & 9 \\
Utility of the app & 0.809 & 8 \\
Safety experience & 0.630 & 3 \\
\hline
\end{tabular}

TABLE 3: Rotated component matrix for the three factors.

\begin{tabular}{|c|c|c|c|}
\hline \multirow[t]{2}{*}{ Statement } & \multicolumn{3}{|c|}{ Component } \\
\hline & 1 & 2 & 3 \\
\hline D1_11. I would download a personal safety app if it ensures an easy access to emergency service (police, fire service). & 0.792 & 0.031 & 0.119 \\
\hline D1_7. I would download a personal safety app that has good online reviews. & 0.792 & 0.191 & -0.047 \\
\hline D1_1. I would download a personal safety app if it meets my expectations. & 0.780 & 0.017 & -0.021 \\
\hline D1_3. I would download a personal safety app because I believe in using any tools that increase my personal safety. & 0.774 & 0.070 & -0.007 \\
\hline D1_10. I would download a personal safety app that is linked to a reputable brand or organisation. & 0.761 & 0.229 & 0.183 \\
\hline D1_8. I would download a personal safety app that is linked to my medical aid. & 0.759 & 0.171 & 0.062 \\
\hline D1_6. I would download a personal safety app recommended by my friends. & 0.752 & 0.166 & 0.061 \\
\hline D1_9. I would download a personal safety app if it is linked to the government medical emergency services. & 0.725 & 0.222 & 0.080 \\
\hline D1_2. I would download a personal safety app because I used a similar app before. & 0.487 & 0.191 & -0.226 \\
\hline C1_8. I use apps that don't take much memory on my gadget. & -0.099 & 0.709 & 0.020 \\
\hline C1_9. I use apps that make my life easier. & 0.265 & 0.704 & 0.156 \\
\hline C1_10. I use apps so that I can talk about them with my friends. & 0.187 & 0.675 & 0.099 \\
\hline C1_6. I try new apps because I know that they can be easily deleted if they do not fulfil my expectations. & 0.168 & 0.632 & 0.101 \\
\hline C1_7. I use apps that are easy to use. & 0.168 & 0.628 & 0.043 \\
\hline C1_11. I like experimenting with apps. & 0.102 & 0.626 & 0.118 \\
\hline C1_5. I use apps when I have clear understanding of their benefits. & 0.194 & 0.621 & 0.227 \\
\hline C1_4. I only use apps when most of my friends have it. & 0.077 & 0.528 & -0.037 \\
\hline B1_1. My university friends have experienced a threat to their personal safety. & -0.036 & 0.114 & 0.757 \\
\hline B1_3. I have personally experienced a threat to my personal safety. & 0.054 & 0.114 & 0.723 \\
\hline B1_2. My family members have experienced a threat to their personal safety. & 0.072 & 0.159 & 0.716 \\
\hline
\end{tabular}

Note: Extraction method: principal component analysis. Rotation method: Varimax with Kaiser normalisation. 
TABLE 5: Reasons preventing participants from using personal safety apps.

\begin{tabular}{ll}
\hline Theme & Reasons \\
\hline Expense or cost & Cost of data \\
& Data expense \\
& Data usage too high \\
& How much it costs to get the app \\
& Phone space \\
Takes much space & App is too big \\
Memory usage & Complicated to use \\
Ease of use & Not responsive \\
& Difficult to understand \\
If the app is not linked to emergency services \\
If there is not a toll-free number \\
No instant response \\
Ondity (meets expectations that fails to meet my expectations \\
If it does not provide the service it is supposed to \\
If it does not meet my needs and expectations \\
Safety of my information \\
Fear of being hacked \\
Not personalised \\
Fear of getting viruses \\
If the app does not have good reviews \\
If it is not proven to be effective \\
An app that is unknown \\
No online reviews \\
\hline Credibility
\end{tabular}

\section{Barriers to adoption of personal safety apps}

The respondents were asked an open question to list three key reasons preventing them from downloading and using a personal safety app. The summary of the responses is presented in Table 5. Although not tasted statistically, the thematic grouping of the open responses is in line with the factors perceived utility of the app and credibility of the app identified through factor analysis. A few respondents pointed to the ease of use as one of the reasons for downloading new apps. Other aspects named by respondents as preventing them from using safety apps are cost or expense, memory usage and privacy concerns. The latter three factors have not been cited in previous studies on adoption technology as factors influencing the adoption of apps.

\section{Discussion}

The first research question aimed to ascertain which safety apps are used by students in Johannesburg. The findings of this study indicate that few students (15\%) downloaded or used safety apps, despite many of them reporting that they experienced threats to their personal safety. Furthermore, the vast majority of the respondents indicated that they have access to suitable devices, are comfortable with using new technology and consider themselves early adopters. In addition, nearly $80 \%$ of respondents indicated that they use a variety of apps in everyday life. Not having a safety app may be partially explained by the lack of awareness of safety apps as nearly three-quarters of respondents were not familiar with any safety apps, but it is also evident from the study that other factors play the role in a low level of adoption of safety apps among the university students.
The EFA identified three factors affecting the adoption of safety apps by university students in Johannesburg. Factor 1 named credibility of the app indicates that the credibility of the app is one of the most important factors in students' decision to adopt a safety ap $p$. The credibility comes from different sources such as peer reviews, online reviews, association with reputable brands and even personal experience with similar apps. The respondents indicated that if the app does not have online reviews or has poor online reviews, they are not willing to download the app. Similarly, peer and word-of-mouth reference play an important role in apps' adoption by millennials. Over $80 \%$ of respondents stated that they would adopt the app that is recommended by their friends. In addition, the respondents indicated a willingness to use the apps associated with a reputable brand such as a scrutiny company, car insurance or a medical aid or insurance company. This finding is in line with previous research by Thusi and Maduku (2020) and Alam et al. (2020) who identified trust in the institutions linked to the apps and the word of mouth, respectively, as key factors in apps adoption.

Factor 2 Perceived utility of the app supports the notion that utilitarian motivations are key reasons for technology adoption, as stated by Verkasalo et al. (2010). This factor also corresponds loosely with the PU factor of the TAM. The respondents indicated that they are more likely to upload the apps that meet their expectations, deliver on the customer promise and fulfil the value proposition. The utility value of the app is understood by millennials broadly and includes elements such as experimenting with the apps and talking to peers about apps. Developers responsible for designing mobile apps may need to invest resources in creating apps that improve millennials' experience. In addition, millennials will have a positive intention to adopt mobile apps, in this case personal safety apps, if they believe that the technology benefits their activities (Thusi \& Maduku 2020).

Factor 3 Safety experience is another latent factor identified in this study and not present in other studies on the adoption of apps. This factor can be explained by the specific focus of the app (personal safety) and the societal context of South Africa, where there is a high prevalence of crime.

Whilst answering the open question about the key barriers to adopting safety apps, the respondents expressed concerns about issues such as safety of the apps, including the integrity of personal information and the risks of malware associated with downloading apps. Some were reluctant to download apps because of spam associated with some apps. Other factors related to the intrinsic qualities of apps are worries about an app using too much memory of the device. This kind of concerns is inherently associated with digital and web-based technologies. The responses to the open question indicate that for many students, the cost of using apps is an important concern. The cost of data is a considerable constraint; therefore, there was high concern about downloading apps that use very much data, even if the apps were free. The cost of use of technology was a factor in the adoption of new technology 
identified in prior research by Steele et al. (2009) and may be even a more prominent factor in the case of users in the developing markets. The thematic grouping of the answers to the open question about the barriers to adoption of personal safety apps coincides with two of the factors identified through the EFA, namely perceived utility and credibility of the app. Furthermore, the responses suggest the influence of other factors such as expense or cost, memory usage and ease of use on the students' decisions to adopt the application.

\section{Conclusion}

Despite high penetration of the South African Market by smart devices and high concern for personal safety, only $15 \%$ of respondents have adopted personal safety apps. This study highlighted that the original dimensions of the TAM model are not sufficient to explain the adoption of safety apps by college students in South Africa. Although the PU of technology relates to the factor perceived utility of the app identified through the EFA applied in this study, other factors were identified, namely the credibility of the app and the safety experience. It is recommended for future research that a confirmatory factor analysis be conducted regarding these factors. In addition, a possible further exploration of dimensions associated with the use of mobile digital technology such as app cost, memory usage and privacy concerns, which were not included in the questionnaire, but emerged as a result of an open question about barriers to the adoption of safety apps by the college and university students in Johannesburg, should be conducted.

Although the findings of this exploratory study identified six factors influencing the adoption of personal safety apps by students in Johannesburg, they cannot be generalised to the whole population because of non-probability sampling and a relatively small sample size.

\section{Acknowledgements}

The authors would like to acknowledge the assistance of $\mathrm{K}$. Dolo, N. Khumalo, K. Masenya, R. Mashaba, K. Mngomezulu, R. Mohosho and R. Mokete, with the field work.

\section{Competing interests}

The authors have declared that no competing interest exists.

\section{Authors' contributions}

All authors contributed equally to this work.

\section{Funding information}

This research received no specific grant from any funding agency in the public, commercial or non-profit sector.

\section{Data availability}

The data that support the findings of this study are available from the corresponding author, A.O., upon reasonable request.

\section{Disclaimer}

The views and opinions expressed in this article are those of the authors and do not necessarily reflect on the official policy or position of any affiliated agency of the authors.

\section{References}

Alam, M.Z., Hoque, Md.R., Hu, W. \& Barua, Z., 2020, 'Factors influencing the adoption of mHealth services in a developing country: A patient-centric study', International Journal of Information Management 50, 128-143. https://doi.org/10.1016/j. ijinfomgt.2019.04.016

Azionya, C.M., 2015, 'University of Johannesburg Millennials' communication of brand perception on Facebook: Implications for reputation management Master's Dissertation, University of Johannesburg, Johannesburg, viewed 07 April 2021, from http://hdl.handle.net/10210/85184

Baabdullah, A.M., 2018, 'Factors influencing adoption of mobile social network games (M-SNGs): The role of awareness', Information Systems Frontiers 22, 411-427. https://doi.org/10.1007/s10796-018-9868-1

Barkhuus, L. \& Polichar, V., 2011, 'Empowerment through seamfulness: Smart phones in everyday life', Personal and Ubiquitous Computing 15, 629-639. https://doi. org/10.1007/s00779-010-0342-4

Batra, A., 2008, 'Foreign tourist's perceptions towards personal safety and potential crime while visiting Bangkok', Anatolia: An International Journal of Tourism and Hospitality Research 19(1), 89-101. https://doi.org/10.1080/13032917.2008.968 7055

Bolton, N.R., Parasurman, A., Hoefnagels, N., Migchels, S., Kabadyi, T., Gruber, Y. et al., 2013, 'Understanding generation $Y$ and their use of social media: A review and research agenda', Journal of Service Management 24(3), 245-257. https://doi. org/10.1108/09564231311326987

Cho, J., Quinlan, M.M., Park, D. \& Noh, G., 2014, 'Determinants of adoption of smartphone health apps among college students', American Journal of Health Behaviour 36(6), 860-870. https://doi.org/10.5993/AJHB.38.6.8

Churchill, G., 1979, 'A paradigm for developing better measures for marketing contrasts', Journal of Marketing Research 16, 64-73. https://doi org/10.1177/002224377901600110

Cohen, L., Manion, L. \& Morrison, K., 2007, Research methods in education, 6th edn., Routledge, London.

Collis, J. \& Hussey, R., 2009, Business research: A practical guide for undergraduate and postgraduate students, Palgrave McMillan, London.

Crime Stats SA, 2019, The 10 worst areas for crime in every province in South Africa, viewed 22 February 2021, from https://www.crimestatssa.com.

Davis, F.D., 1998, 'Perceived usefulness, perceived ease of use and user acceptance of information technology', MIS Quarterly 13(3), 319-339. https://doi. org/10.2307/249008

Delbosc, A. \& Currie, G., 2012, 'Modelling the causes and impact of personal safety perceptions on public transport ridership', Transport Policy 24, 302-209. https:// doi.org/10.1016/j.tranpol.2012.09.009

DHET (Department of Higher Education and Training), 2018, Statistics on post-school education and training in South Africa 2016, viewed 21 February 2021, from http://www.dhet.gov.za/Research\%20Coordination \%20Monitoring $\% 20$ and $\% 20$ Evaluation/6_DHET\%20Stats\%20Report_04\%20April\%202018.pdf.

Dube, R., 2013, Don't be a victim-your smartphone as a personal safety device, viewed 21 February 2021, from http://www.makeuseof.com/tag/dont-be-a-victim-yoursmartphone-as-a-personal-safety-device/.

Ferguson, D.A. \& Greer, C.F., 2016, 'Reaching moving target: How local TV stations are using digital tools to connect with generation $C^{\prime}$, International Journal on Media Management 18(3-4), 141-161. https://doi.org/10.1080/14241277.201 6.1245191

Ford, J.K., Mac Callum, R.C. \& Tait, M., 1986, 'The application of exploratory factor analysis in applied psychology: A critical review and analysis', Personnel Psychology 39, 291-314. https://doi.org/10.1111/j.1744-6570.1986.tb00583.x

Geffen, D. \& Straub, D., 2005, 'A practical guide to factorial validity using pls-graph: Tutorial and annotated example', Communications of the Association for Information Systems 16, 91-109. https://doi.org/10.17705/1CAIS.01605

Ghalandari, K., 2012, 'The effect of performance expectancy, effort expectancy, social influence and facilitating conditions on acceptance of e-banking services in Iran: The moderating role of age and gender', Middle-East Journal of Scientific Research 12(6), 801-807.

Harris, M.A., Brookshire, R. \& Chin, A.G., 2016, 'Identifying factors influencing consumers' intent to install mobile applications', International Journal of Information Management 36, 441-450. https://doi.org/10.1016/j. ijinfomgt.2016.02.004

Henson, R.K. \& Roberts, J.K., 2006, 'Use of exploratory factor analysis in published research common errors and some comment on improved practice', Educational and Psychological Measurement 66(3), 393-416. https://doi. org/10.1177/0013164405282485

ICASA (Independent Communications Authority of South Africa), 2018, 3rd Report on the state of ITC sector in South Africa, viewed 21 February 2021, from https:// www.icasa.org.za/uploads/files/State-of-ICT-Sector-Report-March-2018.pdf. 
Jansson, M., Fors, H., Lindgren, T. \& Wistrom, B., 2013, 'Perceived personal safety in relation to urban woodland vegetation - A review', Urban Forestry \& Urban Greening 12, 127-133. https://doi.org/10.1016/j.ufug.2013.01.005

Kim, H.J. \& Yoon, M.N., 2014, 'Adopting smartphone-based blended learning: An experimental study of the implementation of Kakao-Talk and Mocafe', Multimedia Assisted Language Learning 17(2), 86-111. https://doi.org/10.15702/ mall.2014.17.2.86

Kim, J., Kim, S. \& Rogol, E., 2017, 'The effects of consumer innovativeness on sport team applications acceptance and usage', Journal of Sport Management 31, 241-255. https://doi.org/10.1123/jsm.2015-0338

Komiak, S.Y.X. \& Benbasat, I., 2006, 'The effects of personalization and familiarity on trust and adoption of recommendation agents', MIS Quarterly 30(4), 941-960. https://doi.org/10.2307/25148760

Kwateng, O.M., Atiemo, K. \& Appiah, C., 2018, 'Acceptance and use of mobile banking: An application of UTAUT2', Journal of Enterprise Information Management 32(1) 118-151. https://doi.org/10.1108/JEIM-03-2018-0055

Lepp, A., Barkley, J.E. \& Karpinski, A.C., 2014, 'The relationship between cell phone use, academic performance, anxiety, and satisfaction with life in college students' Computers in Human Behavior 31, 343-350. https://doi.org/10.1016/j. chb.2013.10.049

Maduku, D.K., 2016, 'The effect of institutional trust on internet banking acceptance: Perspectives of South African banking retail customers', South African Journal of Economic and Management Sciences 19(4), 533-548. https://doi.org/10.4102/ sajems.v19i4.1558

Mafe Ruiz, C., Sanz Blas, S. \& Fernando Tavera-Mesías, J., 2010, 'A comparative study of mobile messaging services acceptance to participate in television programmes', Journal of Service Management 21(1), 69-102. https://doi. org/10.1108/09564231011025128

McCarthy, O.T., Caulfield, B. \& O'Mahony, M., 2016, 'How transport users perceive personal safety apps', Transport Research Part F 43, 166-182. https://doi. personal safety apps', Transpor
org/10.1016/j.trf.2016.10.005

McCorkindale, T., DiStaso, M.W. \& Sisco, H.F., 2013, 'How millennials are engaging and building relationships with organizations on Facebook', Journal of Social Media in Society 2(1), 66-87.

McCormick, E., 2015, 'Invasion of the millennials', in 4th Quarter, pp. 28-34, viewed 21 February 2021, from Bank Director.Com.

Moore, M., 2012, 'Interactive media usage among millennial consumers', Journal' of Consumer Marketing 29(6), 436-444. https://doi.org/10.1108/ 0736376121125924

Moreno, F.M., Lafuente, J.G., Carreón, F.'A. \& Moreno, S.M., 2017, 'The characterization of the millennials and their buying behavior', International Journal of Marketing Studies 9(5), 135-144. https://doi.org/10.5539/ijms.v9n5p135

Ogbeide, G., Fenich, G.G., Scott-Halsell, S. \& Kesterson, K., 2013, 'Communication preferences for attracting the millennial generation to attend meetings and events', Journal of Convention and Event Tourism 14, 331-344. https://doi.org/10.1080/1 5470148.2013.843480

Oksiutycz, A. \& Kunene, S., 2017, 'Contribution of online corporate communication to brand reputation among millennials in the Vaal Region', Communicatio 43(3-4), 74-94. https://doi.org/10.1080/02500167.2017.1340318

Pallant, J., 2013, SPSS survival manual: A step by step guide to data analysis using SPSS, 5th edn., Allen \& Unwin, Crows Nest.

Park, J., Gunn, F., Lee, Y. \& Shim, S., 2015, 'Consumer acceptance of a revolutionary technology-driven product: The role of adoption in the industrial design technology-driven product: The role of adoption in the industrial design doi.org/10.1016/j.jretconser.2015.05.003

Petaschnick, J., 2017, 'Communicating across generations', The Receivables Report for America's Healthcare Financial Managers 32(1), 8-11.
Potter, S.J., Moschella, E.A., Smith, D. \& Draper, N., 2020, 'Exploring the usage of a violence prevention and response app among community college violence, prevention and response app among community college
students', Health Education \& Behavior 47(1S), 44S-53S. https://doi. students', Health Education $\&$
org/10.1177/1090198120910995

Purani, K., Kumar, D.S. \& Sahadev, S., 2019, 'E-loyalty among millennials: Personal characteristics and social influences', Journal of Retailing and Consumer Services 48, 215-223. https://doi.org/10.1016/j.jretconser.2019.02.006

Schewe, C.D. \& Meredith, G., 2004, 'Segmenting global markets by generational cohorts: Determining motivations by age', Journal of Consumer Behaviour 4 51-63. https://doi.org/10.1002/cb.157

Statista, 2015, Most popular Apple App store categories in March 2015, by share of available apps, viewed 21 February 2021, from http://www.statista.com/ statistics/270291/popularcategories-in-the-app-store/.

Statista, 2020, Number of smartphone users in South Africa from 2014 to 2023, viewed 21 February 2021, from https://www.statista.com/statistics/488376/forecast-ofsmartphone-users-in-south-africa/.

Stats SA (Statistics South Africa), 2017a, Mid-year population estimates 2017, viewed 21 February 2021, from http://www.statssa.gov.za/publications/P0302/ P03022017.pdf.

Stats SA (Statistics South Africa), 2017b, And the streets fell silent: How crime impacts the everyday, viewed 21 February 2021, from http://www.statssa.gov.za/?p=9553.

Steele, R., Lo, A., Secombe, C. \& Wong, Y.K., 2009, 'Elderly persons' perception and acceptance of using wireless sensor networks to assist healthcare', Internationa Journal of Medical Informatics 78(12), 788-801. https://doi.org/10.1016/j. ijmedinf.2009.08.001

Saunders, M., Lewis, P. \& Thornhill, A., 2003, Research methods for business students, Prentice-Hall, Harlow.

Tan, E. \& Lau, J., 2016, 'Behavioural intention to adopt mobile banking among the millennial generation', Young Consumers 17(1), 18-31. https://doi.org/10.1108/ YC-07-2015-00537

Tarhini, A., Hone, K. \& Liu, X., 2014, 'Measuring the moderating effect of gender and age on e-learning acceptance in England: A structural equation modeling approach for an extended technology acceptance model', Journal of Educational Computing Research 51(2), 163-184. https://doi.org/10.2190/EC.51.2.b

Tech Target, 2018, Definition: App, viewed 21 February 2021, from https:// searchmobilecomputing.techtarget.com/definition/app.

Thusi, P. \& Maduku, D.K., 2020, 'South African millennials' acceptance and use of retail mobile banking apps: An integrated perspective', Computers in Human Behaviour 111, 106405. https://doi.org/10.1016/j.chb.2020.106405

Venkatesh, V., Thong, J.Y. \& Xu, X., 2012, 'Consumer acceptance and use of information technology: Extending the unified theory of acceptance and use of technology', MIS Quarterly 36(1), 157-178. https://doi.org/10.2307/41410412

Verkasalo, H., Lopez, N.C., Molina-Castello, F.J. \& Bouwman, H., 2010, 'Analysis of users and non-users of smartphone applications', Telematics and Informatics 27(3), 242-255. https://doi.org/10.1016/j.tele.2009.11.001

Vesanen, M., 2018, 'Predictors of online insurance service use intentions among young consumers', Master's thesis, viewed 07 April 2021, from http://urn.fi/ URN:NBN:fi:aalto-201806273635.

Voigt, K., 2013, Report: Apps industry surging to \$25 billion, viewed 07 April 2021 from http://www.cnn.com/2013/03/05/business/global-apps-industry/index. $\mathrm{html} /$.

Williams, B., Onsman, A. \& Brown, T., 2010, 'Exploratory factor analysis: A five-step guide for novices', Journal of Emergency Primary Health Care 8(3), article 990399. https://doi.org/10.33151/ajp.8.3.93 